\title{
TEXTURAL DEPENDENCE OF SHEAR STRENGTH AND CONSOLIDATION OF COLLIERY WASTES FOR USE AS CONSTRUCTION MATERIALS
}

\author{
E. O. Eze* \\ Department of Civil Engineering, University of Benin, BEnin City, Edo State. NIGERIA.
}

E-mail address:eoeze@yahoo.com.

\begin{abstract}
Minestone and tailing from Enugu coal field were studied for the evaluation of their suitability as geotechnical engineering material based on their texture, shear strength and consolidation. The $\mathrm{pH}$, sulphate content, specific gravity, particle size distribution, consistency limits, compaction and consolidation tests of these wastes were first carried out. Direct shear strength tests were then done on the grain size ranges of $>4.25 \mathrm{~mm}, 4.25 \mathrm{~mm}-600 \mu \mathrm{m}$, $600-150 \mu \mathrm{m}$ and $<150 \mu \mathrm{m}$ of the wastes. Results showed that the mine stone was non-plastic and the tailing medium plastic materials, and that they compacted to fairly high density of $1.45-1.57 \mathrm{Mg} / \mathrm{m}^{3}$, respectively. The effective peak and residual friction angles of the mine stone ranged between $42^{\circ} 07^{\prime}-38^{\circ} 17^{1}$ and $38^{\circ} 40^{1}-37^{\circ} 11^{1}$, respectively. The tailing had peak shear strength ranging from 0 to $85 \mathrm{kN} / \mathrm{m}^{2}$ and friction angles less than the minestone. The results showed that the wastes are good for subgrade, sub-base, filling, and for earth dam and embankment construction.
\end{abstract}

Keywords: minestone, suitability, engineering material, texture, shear strength, sub base

\section{INTRODUCTION}

Environmental concern and sustainable construction are the main issues underlying the current requirement for critical review of prevailing practices, techniques and sources of raw materials. Focus has shifted to industrial wastes and byproducts which hitherto received little or no attention. Colliery waste is one of such materials. Despite its huge abundance in operating and abandoned coalfields, its potential as raw material in civil engineering construction and other industries is yet to be fully realised [1].

Interest in the use of non-granular materials, like colliery spoil, has grown recently due not only to their relative abundance on the surface but also because of their growing generation in mining and construction works. In some industrialized countries landfill tax and a tax on use of primary aggregates have placed increasing financial pressure on highway engineers to provide the most economic alternatives to the traditional road making materials [2]. Since friction is the main factor in the use of granular soils in geotechnical works, earlier specifications and designs for their use were based on the properties of a wide range of used and tested granular soils and aggregates. As the properties of wastes were studied, it became obvious that a considerable relaxation and broadening of the earlier specifications could be done safely.

One result of such studies has been the acceptance of the less amenable, low-plasticity soils in applications dominated by granular soils [2]. The use of these alternative materials clearly leads to substantial savings in the cost of importing granular materials and disposing of low-plasticity geomaterials such as colliery wastes. This study aims to evaluate the suitability of coalmine wastes from Enugu as geotechnical material based on their texture, shear strength and consolidation. The textural dependence of shear strength and consolidation of the wastes is also established.

\section{METHODOLOGY}

\subsection{Samples}

Samples of the minestone (or run-of-the mine) and the tailing were collected fresh from Onyeama mine in disturbed state. Minestone, also called coarse discard, is the component of coal mine waste obtained by separating the coal from the associated rocks directly 
at the mine. The dominant constituents of the waste are fireclay, black shale and sandstone. Pieces of coal of various sizes make up a minor proportion of the mine stone. Texturally, mudstone is predominantly of sand-gravel sizes, typically between 100-1000 $\mu \mathrm{m}$ in size [3]. After the separation at the mine, the coal together with adhering sand, shale and fireclay, as well as other dirts is taken to the washery for washing prior to shipment to users. The solids settled or filtered from the dirty water from the washing process is called the tailing or finr discard. It constitutes the fine discard of the colliery waste ad comprises clay, silt, and fine sand-size pieces, mostly $<2 \mathrm{~mm}$ of stone and clay, together with some very fine coal, too small to process economically. The residual coal content in the fine discard may be up to $30 \%$ or more of its total [4].

The samples were transported immediately in secured bags to Geotechnical Engineering Laboratory of the University of Benin, Benin City where they were tested. Iron sulphide minerals- pyrite(fool's gold) and marcasite -readily identified by their metallic lustre and vivid yellow hue-were observed to be present in patches and in disseminated form, particularly in the coal and the dark shale (or roof shale) components of the wastes. Pyrite and marcasite are iron disulphides, distinguished one from the other by pyrite $\left(\mathrm{FeS}_{2}\right)$ being cubic in form, and marcasite $\left(\mathrm{FeS}_{2}\right)$ belonging to the orthorhombic system [5]. The wet samples had ash gray colour which turned dirty white on drying.

\subsection{Laboratory Tests}

The following tests were carried out on the bulk wastes: natural moisture content, specific gravity, $\mathrm{pH}$, sulfate content, particle size distribution, consistency limits, standard proctor compaction, direct shear strength, and consolidation. The test procedures adopted in these tests, except the shear strength, were in accordance with BS 13771990 [6]. For the shear strength test the procedures followed was the standard ASTM D 3080-03 2004 [7]. Thereafter, the samples were separated into size fractions of $>4.25$ $\mathrm{mm}, 4.25 \mathrm{~mm}-600 \mu \mathrm{m}, 600-150 \mu \mathrm{m}$, and $<150 \mu \mathrm{m}$. These size fractions were studied for the dependence of the shear resistance parameters on them. Both direct shear strength and oedometer or consolidometer tests were determined on specimens placed at the standard proctor optimum moisture content.

The shear strength test consisted of shearing the test specimen, prepared to specification, in a direct shear box under stress controlled conditions. The shear residual strength was carried out on the waste by placing the specimen in a direct shear box and shearing it back and forth several times until a well defined shear failure surface was developed. The residual strength, therefore, is the shear strength remaining after a prolonged amount of shearing deformation has occurred. The drained residual shear strength was then obtained by performing a final slow shear of the specimen. Data from these tests were plotted first as the shear stress /shear strain curves from which were derived the effective peak/residual shear strength and the effective peak/residual angles of internal friction. Details of the test are given in the ASTM test specifications.

In the consolidometer test, specimens of the wastes compacted at predetermined standard proctor optimum of $18 \%$ was trimmed and placed into a confining ring. Concentric vertical loads were applied to the soil through the loading device. Consolidation of the test specimen was carried out for the load increments of 12, 25, 50, 100 and $200 \mathrm{kPa}$. Each load increment remained on the specimen for 24 hours. Test results were plotted as void ratio versus log of pressure curves from which were obtained the compression index $\mathrm{C}_{\mathrm{c}}$ and the coefficient of volume compressibility $\mathrm{m}_{\mathrm{r}}$ in $\mathrm{m}^{2} / \mathrm{MN}$ unit.

The $\mathrm{SO}_{3}$ content was determined by shaking one part by mass of the wastes with two parts by mass of water. Care was taken to extract the sulfate ions from the wastes to restrict the influence of the sparingly soluble calcium sulphate on the result.

\section{TEST RESULTS AND ANALYSIS}

The results of the tests are presented as tables and figures below. Table 1 lists the general properties of the wastes. These results indicate that the wastes are medium to low plasticity materials. Fig. 1 shows the grain size distribution curves of the mine wastes. Each curve is the average of 3 tests each of the minestone and the tailing. The shape of the curves shows fairly well graded materials, with the washery being slightly gap graded about the fine sand-coarse silt size range. Fig. 2 shows that the tailing compacts to a significantly higher dry density $\left(1.57 \mathrm{Mg} / \mathrm{m}^{3}\right)$ relative to the coarser-grained minestone $\left(1.45 \mathrm{Mg} / \mathrm{m}^{3}\right)$. The dependence of the shear strength parameters on the textural characteristic of the mine wastes can be seen in Figs 3-6, while the consolidation curves of the colliery spoil are presented in Figs 7 and 8. 
Table 1 Properties of the wastes

\begin{tabular}{lcc}
\hline Property & Minestone & Tailing \\
\hline Specific gravity & 2.21 & 2.26 \\
pH & 5.7 & 6.4 \\
Sulphate content, \% & 1.9 & 3.2 \\
< No 200 sieve size, \% & 35 & 40 \\
Uniformity coefficient, $\mathrm{C}_{\mathrm{u}}$ & $<0.001$ & $<0.001$ \\
Liquid limit, \% & $\mathrm{NP}$ & 35 \\
Plasticity index, \% & $\mathrm{NP}$ & 14 \\
GI & 0 & 1 \\
AASHTO soil class & $\mathrm{A}-2-4$ & $\mathrm{~A}-6$ \\
Linear shrinkage, \% & 4.5 & 8.7 \\
MDD, Mg/m ${ }^{3}$ & 1.45 & 1.57 \\
OMC, \% & 20.3 & 19.2 \\
Compression index, $\mathrm{C}_{\mathrm{c}}$ & 0.027 & 0.005 \\
Coeff, vol compress. x 10- & & \\
${ }^{3} \mathrm{~m}^{2} / \mathrm{MN}$ & 0.088 & 0.090 \\
Permeability, x10-3 $\mathrm{cm} / \mathrm{s}$ & & \\
\hline
\end{tabular}

\section{DISCUSSION OF THE RESULTS}

\subsection{Properties}

As the rocks enclosing the coal form the bulk of colliery spoil they determine largely the properties and behavior of mine wastes. The shape of the grain size spread of the tailing is similar to those typical of soils from corrugating sections of pavements over laterite, while the minestone's is typical of soils known to perform satisfactorily as sub base [8].The coefficients of uniformity and the curvature also indicate well graded materials. The practical particle size that can be determined in the hydrometer test is $0.001 \mathrm{~mm}$ [9]. From Fig. 1 the percent of the waste particles passing this particle size is more than $10 \%$, and so the effective size $D_{10}$ could not be read. Consequently the coefficient of uniformity could not be determined. For such soils the uniformity coefficient is reported as $<0.001 \mathrm{~mm}$ [9]. The gap grading, means higher permeability of the fill or embankment built using the tailing.

The $\mathrm{pH}$ and the $\mathrm{SO}_{3}$ values of the 2:1 soil water extract rate as moderate to severe in terms of their potential for acid attack on concrete structures in, or in contact with the wastes. Higher soil water sulphate contents and pHless than 4.3 indicate presence of free sulphuric acid which can be very aggressive to concrete. On the basis of their $\mathrm{SO}_{3}$ contents, normal Portland cement and sulphateresisting cement are required for concrete structures in or in contact with the minestone and the tailing. Normal Portland cement is the option where the structures are placed wholly above the ground water level while sulphate resisting cement is used if the concrete structures are to be in contact with fluctuating water level [10].

The wastes have consistency limit, linear shrinkage and group index values which also indicate lowplasticity material. The group index is used within the AASHTO soil classes to further evaluate the relative quality and supporting value of sub-grade material. For cohesive soils the expected performance is inversely related to the group index (GI) [11], lower value, 0 indicating excellent materials and highest value, 20 denoting very poor sub-grade soils. Fig. 2 shows that the more plastic tailing has higher compaction dry density than the coarser minestone. Ordinarily, coarser soils have higher dry density than fine graded soils when both are compacted to the same effort. However, the wastes are heterogeneous in composition and relative proportions as well as the grain sizes of the coal in the wastes may be responsible for the observed material behavior. The maximum dry density values of the wastes (1.45 and $1.57 \mathrm{Mg} / \mathrm{m}^{3}$ ) are slightly higher than, but compare well with those of the soft clays of Southern Illinois' similar bituminous coal wastes (1.34 and 1.45 $\left.\mathrm{Mg} / \mathrm{m}^{3}\right)$, respectively [12]. The little difference can be due to the nature of underlying clays in the coalfields. In the coalfields shale and the fireclay constitute the bulk of the wastes. The under clay in Enugu coalfield is quite strong, dense and compacts to higher density. Following the Aberfan disaster in 1966 colliery spoils are now typically compacted to high densities, with corresponding relatively low air voids, as precaution against tip instability [13]. Despite this, colliery waste failures remain common, as the one which occurred in the Chinese village of Taoshi in 2008, claiming 218 lives [14].

Figs 3-6 show that for all the size fractions the minestone derived its shear strength from the angle of internal friction only, this being highest in the 600$150 \mu \mathrm{m}$ size range, with the values of $42^{\circ}$ and $38^{\circ}$ for the peak and residual friction angles, respectively. This is an in indication that the minestone is a granular material. The peak shear strength of the tailing ranged from 0 to $85 \mathrm{kN} / \mathrm{m}^{2}$, and friction angles less than the minestone. These shear strength parameters compare well with reported strength values of $0-153 \mathrm{kN} / \mathrm{m}^{2}$ and $20-42^{\circ}$ for lateritic sandy clays [8]. 


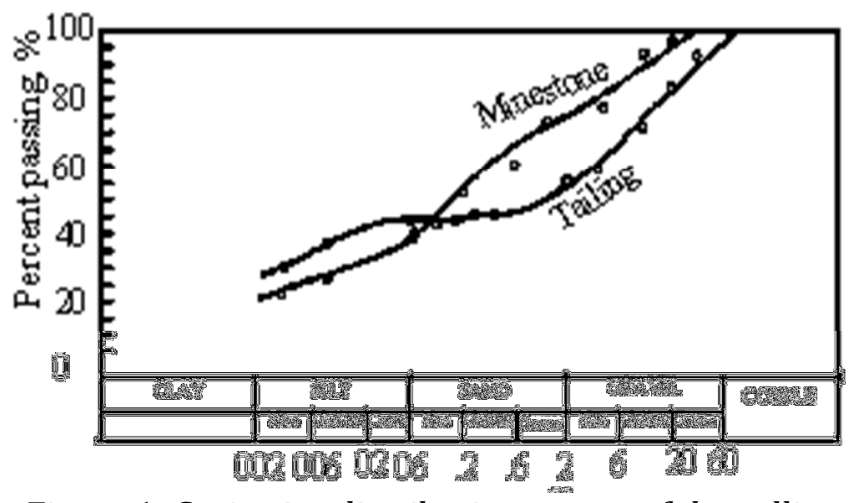

Figure 1: Grain size distribution curves of the colliery waste

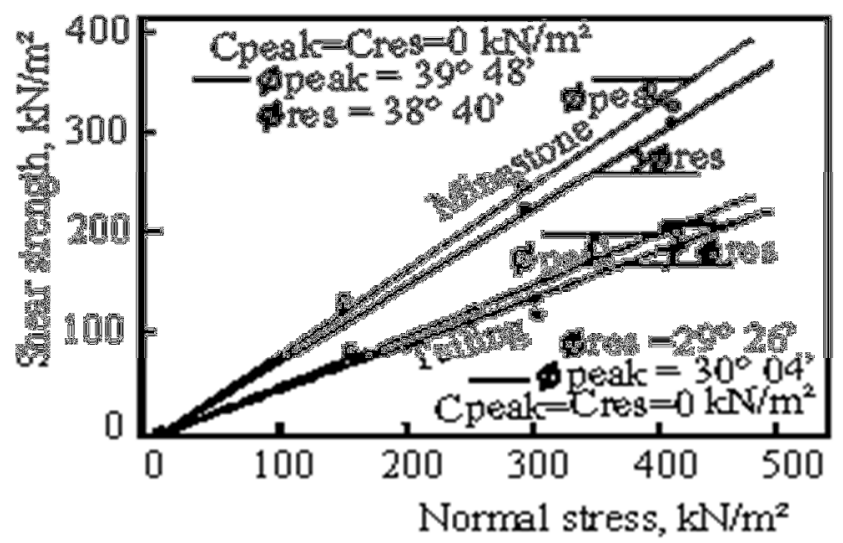

Figure 3: Mohr envelopes for the $>4.25 \mathrm{~mm}$ fraction of the wastes

the tailing was derived from both the cohesion and internal friction angle for all the size ranges, except the $>4.25 \mathrm{~mm}$ size, where the cohesion was zero. This shows that the tailing is a cohesive granular soil. For both wastes the shear strength parameters generally decreased with decreasing particle size. The shear resistance behavior (shear stress/shear strain curves not shown) exhibited by the compacted wastes is similar to that of dense sand. As the resistance to shearing built up in the waste to a peak the waste dilated, and the density as well as the shearing resistance also dropped. This is in contrast to the shearing process in loose sand in which the particles contract and the shearing resistance builds up slowly to failure without any peak being attained. The critical density and the associated critical void ratio of the wastes lie between these two extremes [15].

The drained residual shear strength as determined for the wastes is applied to many types of soil conditions where a considerable amount of shear deformation has already occurred. The stability analysis of ancient landslides, slopes in over consolidated, fissured clays, and slopes in fissured shales are some examples

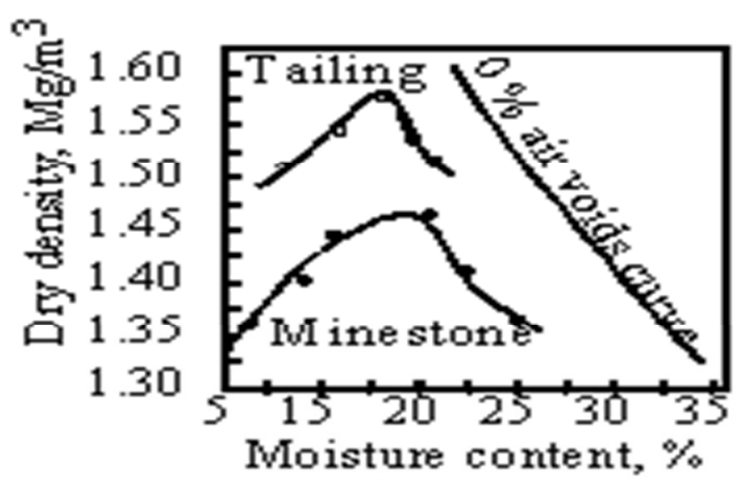

Figure 2:Moisture-density curves for the colliery wastes

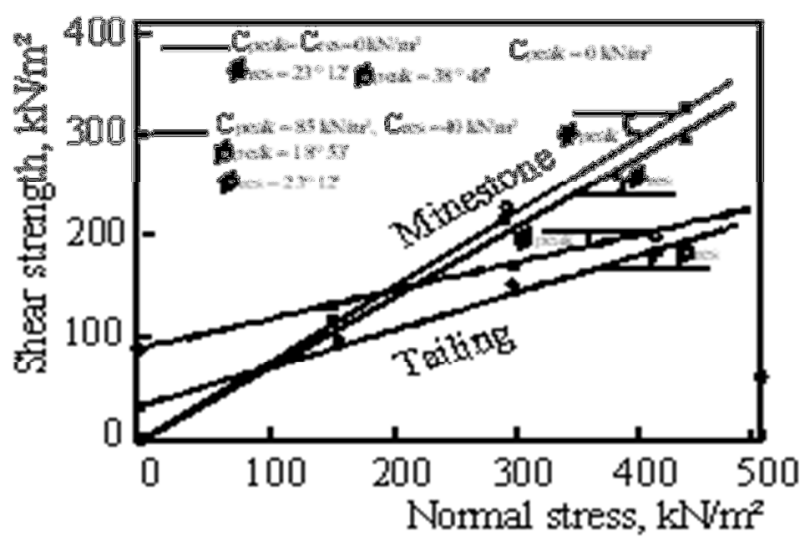

Figure 4: Shear strength parameters for the 4.25 mm-600um fraction of the waste

where the stability analysis needs to be based on the drained residual shear strength of failure surfaces. As the peak, the ultimate and the residual shear strengths increase with increasing normal stress (overburden or depth) the shear strength test is best carried out at the normal stress appropriate for the problem at hand; otherwise there would be the tendency to tenuously extrapolate to stresses to which no results are available.

The curved shape of the e - $\log$ P plots (Figs. 7 and 8) is that of overconsolidated clays. However, the odd shape of the tailing is hard to explain. The initial straight line portion of the curve and the subsequent drop in the void ratio may be due to initial resistance to compression offered by the coal particles and their subsequent collapse at pressure level higher than their crushing strength. Following the collapse of the mixed soil structure, the compression load applied to tailing is transferred to its clay component and the consolidation curve assumes the usual shape characteristic of cohesive materials. The wastes have low compression index $\left(\mathrm{C}_{\mathrm{c}}\right)$ of 0.027 and 0.005 , an indication of their low compressibility typical of 
heavily consolidated at depth. The values of the coefficient of volume compression $\left(\mathrm{M}_{\mathrm{v}}\right)$ are 0.088 and $0.090 \times 10^{-3} \mathrm{~m}^{2} / \mathrm{MN}$ for the minestone and the tailing respectively. These also indicate low compressible materials [10]. Preconsolidation pressures of 1050 and $235 \mathrm{kN} / \mathrm{m}^{2}$ were computed via Casagrande's technique for the minestone and the tailing, respectively. This implies that if the wastes were natural deposits, they should not be subjected to pressures higher than the respective preconsolidation loads to prevent excessive settlement. Preconsolidation of the lateritic clays is usually attributed to desiccation rather than past overburden [8].

Apart from desiccation, overconsolidation of tropical soils is attributed also to changes in groundwater level in the geological past. The mechanisms by which the overconsolidation can be effected in, for example, the fireclay component of the wastes can be explained using Fig. 9. In the figure the upper portion of the fireclay layer may become desiccated under hot and dry weather conditions. Nigeria's sub-bituminous coal is Cretaceous in age [16]. The Cretaceous Period about 145-66 million years ago- is unique for the remarkable processes and events that occurred during this time. Most of the events and processes were global in nature. Tropical sea surface and deep water temperatures were then about $15-20^{\circ} \mathrm{C}$ higher than they are today [17]. These provided good condition for desiccation of the waste material source rocks.

The Cretaceous is also characterized by numerous rises and falls of sea level, about 5-15 of them. Generally, the oceans were 100-200 m and 200-250 m higher than the present at the beginning and at the end, respectively of the period [18]. At the maximum sea level rise, landmass covered only about $18 \%$ of the planet's surface, against today's roughly $28 \%[19]$. Referring to Fig. 9a, the rising water level would subject the sand stratum above the fireclay to buoyant condition thereby reducing the load on the clay. This would result in over consolidated of the fireclay because the vertical effective stress is now lower with the permanent rise in the groundwater table. When the groundwater table is lowered, Fig. 9b the total stress in the top sand practically would remain unchanged but the effective stresses would increase. Since water escapes slowly from the underlying clay bed, the effective stress takes a long time to reach the new equilibrium state, resulting in overconsolidated condition in the fireclay. The presence of the iron minerals in the wastes can have significant control over the properties and behavior of the wastes. On exposure to air pyrite oxidizes to sulfur dioxide which mixes with water to form weak sulphuric acid.

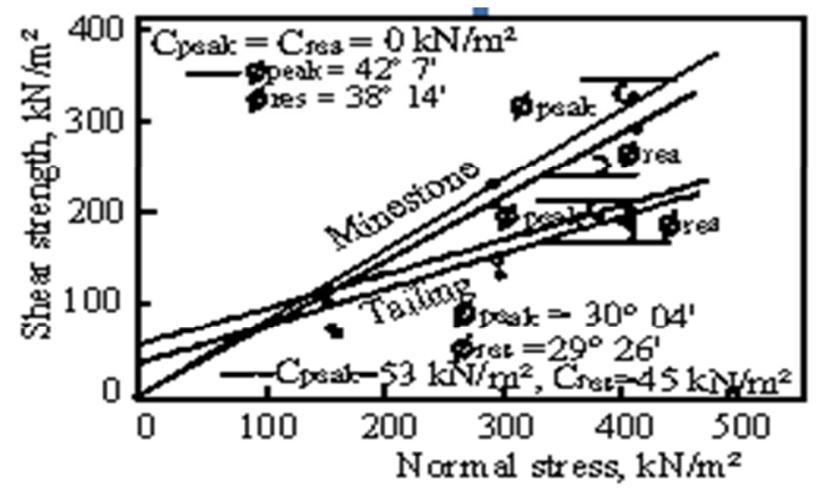

Figure 5: Mohr envelopes for the 600-150 $\mu \mathrm{m}$ size range of the wastes

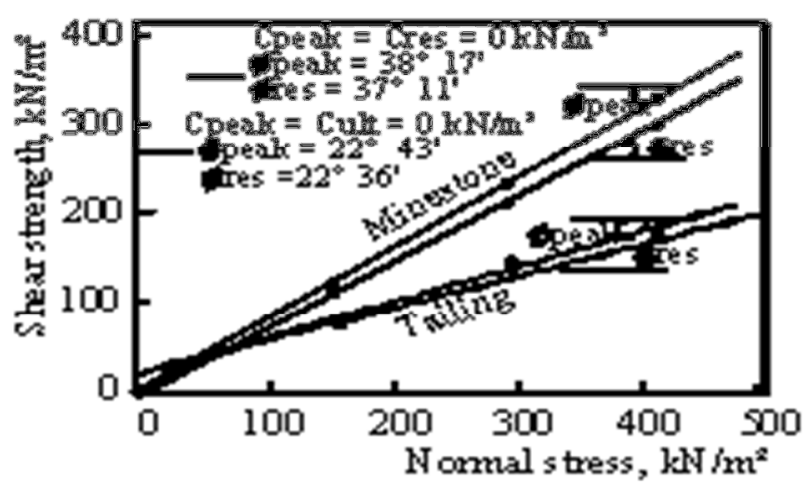

Figure 6: Mohr envelopes for the $<150 \mu \mathrm{m}$ fraction of the wastes

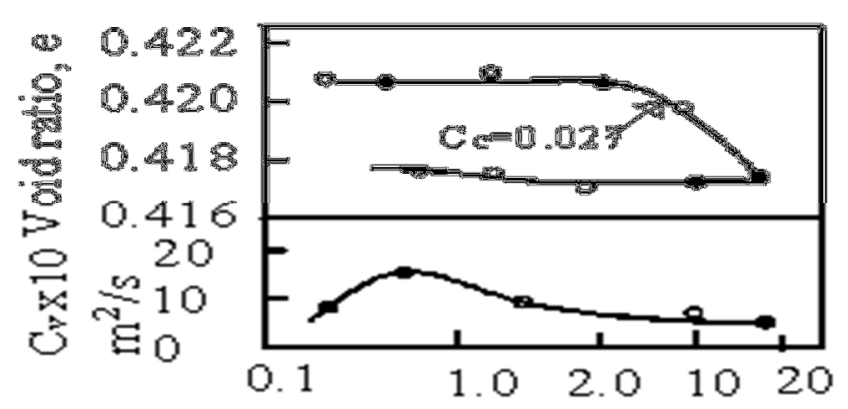

Figure 7: and e-log $P$ and $C_{V}$-log $P$ curves for the coarse discard

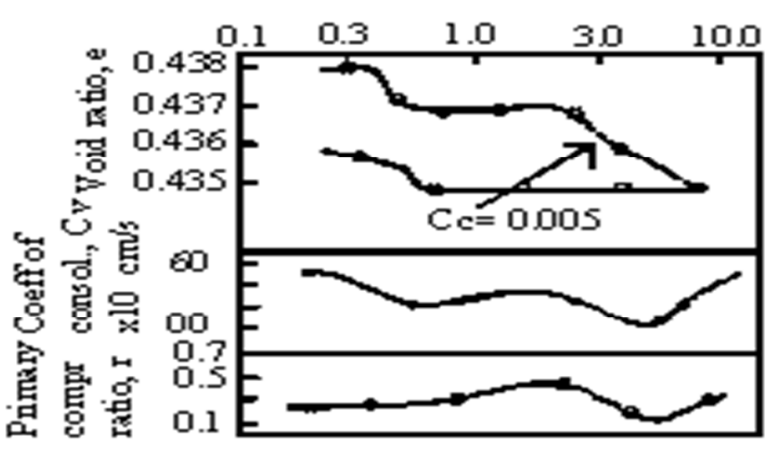

Figure 8: e-log P, CV-log P and r-log P curves of the tailing 
Water percolating through such waste is enriched in sulphuric acid which results in acid mine drainage (AMD) characteristic of spoil tips. Where oxidation of the iron mineral proceeds with insufficient water the expansive intermediate product fills the voids and appreciably reduces the permeability of the waste [20]. On the other hand, oxidation and aging can have beneficiating effect on the wastes. A $30 \%$ increase in the compressive strength of aged spoil tip has been recorded over that of freshly tipped spoil [3].

\subsection{Uses of the wastes in civil engineering constructions}

The minestone meets the Federal Ministry of Works and Housing (Nigeria) specification for sub-grade and sub-base on the basis of fines content not exceeding $55 \%$, and liquid limit and plasticity index of less than $35 \%$ and $12 \%$, respectively. The tailing also meets these, except its slightly higher plasticity index of 14 $\%$. Based on these, the non-plastic minestone is good, too, as fill material in quarries, and embankments, and in reclaiming low lands where less stringent specifications are called for. The use of minestone as sub-base is now accepted widely in many countries [21]. The potential of the wastes for use as base course materials is further considered in terms of their grain size spread and plasticity characteristics. Table 2 lists criteria used for rating lateritic soils for road base construction. The criteria are the products of the percent passing No 200 sieve and either the LL or the PI. The minestone has (PI x \% passing 200) of 0 , and the tailing 560. The (LL x \% passing 200) of the minestone is again 0 ,and for tailing it is 1440 .

Table 2: The criteria for rating laterite soils for road base construction

\begin{tabular}{llll}
\hline Criterion & Class I & Class II & Class III \\
\hline $\begin{array}{l}\text { (PI) } \times(\%<\text { No } 200 \\
\text { sieve) }\end{array}$ & $200 \max$ & $400 \max$ & $600 \max$ \\
$\begin{array}{l}\text { (LL) } \times(\%<\text { No } 200 \\
\text { sieve) }\end{array}$ & $600 \max$ & $900 \max$ & $1250 \max$ \\
\hline
\end{tabular}

Source [22]

Table 3: Range of some geotechnical properties of laterite soils used in earthdam construction

\begin{tabular}{ll}
\hline Property & Range \\
\hline LL, \% & $28-90$ \\
PI, \% & $10-37$ \\
Dry density, $\mathrm{kg} / \mathrm{m}^{3}$ & $1100-1800$ \\
\hline
\end{tabular}

Source [22]

The minestone rates as Class I material while the tailing falls into Class III. The minestoneon the bases of these criteria are therefore good for base course construction. Consideration is made, too, to the suitability of the wastes for earthdam construction. For use in earthdam construction lateritic soils are rated on the bases of their plasticity characteristics and compacted dry density as presented in Table 3.

The dry density values 1.45 and $1.57 \mathrm{Mg} / \mathrm{mm}^{3}$, the PI of $0 \%$ and $14 \%$, and the LL of $0 \%$ and $36 \%$ of the mine waste and the tailing, respectively fall within the respective value brackets in Table 3 . On these bases therefore the colliery wastes are suitable for use in earthdam construction.

To provide strength and durability for heavy vehicular traffic, unbound minestone can be stabilized with additives- cement, lime, tar or bitumen [1]. The fresh and unburnt wastes studied have some advantages over burnt wastes. Unburnt mine waste has less variable properties, lower soluble sulfate concentration, and compact to higher density [13]. However, some problems have been identified in the use of unburnt waste in civil engineering construction. First, there is a possibility of in-service weathering and degradation of the mine wastes, especially if the degradable contents of the iron minerals are present in considerable amounts. Alteration of both the physical and strength/stiffness properties of the wastes due to biodegradation becomes more significant if the resultant properties differ significantly from those upon which the embankments or similar structures were originally designed.

Excessive wear, expansive behaviour, leaching and radioactivity are other common problems associated with the use of colliery wastes in construction. Dangerous concentration of sulphate in ground floor slabs due to drying out has been reported where mine wastes were used as fill.

This has caused the expansion of ground floor concrete leading to outward lifting of the foundation walls [23]. Also the multipurpose use of minestone in earth structures such as in building of river and road embankments, and for levelling ground for future housing or industrial

development has drawn special attention to the problem of frost susceptibility and frost heave in some cases. It has been demonstrated that if the unburnt colliery spoils have $<20 \%$ of the minus 200 sieve size content, they are likely to show substantial heave, otherwise they are unlikely to be frost susceptible [24]. Stringent specifications with respect to the degree of compaction are now imposed on minestone used in civil engineering construction [21]. This is aimed at reducing voids and preventing water percolation into the works incorporating mine wastes. 

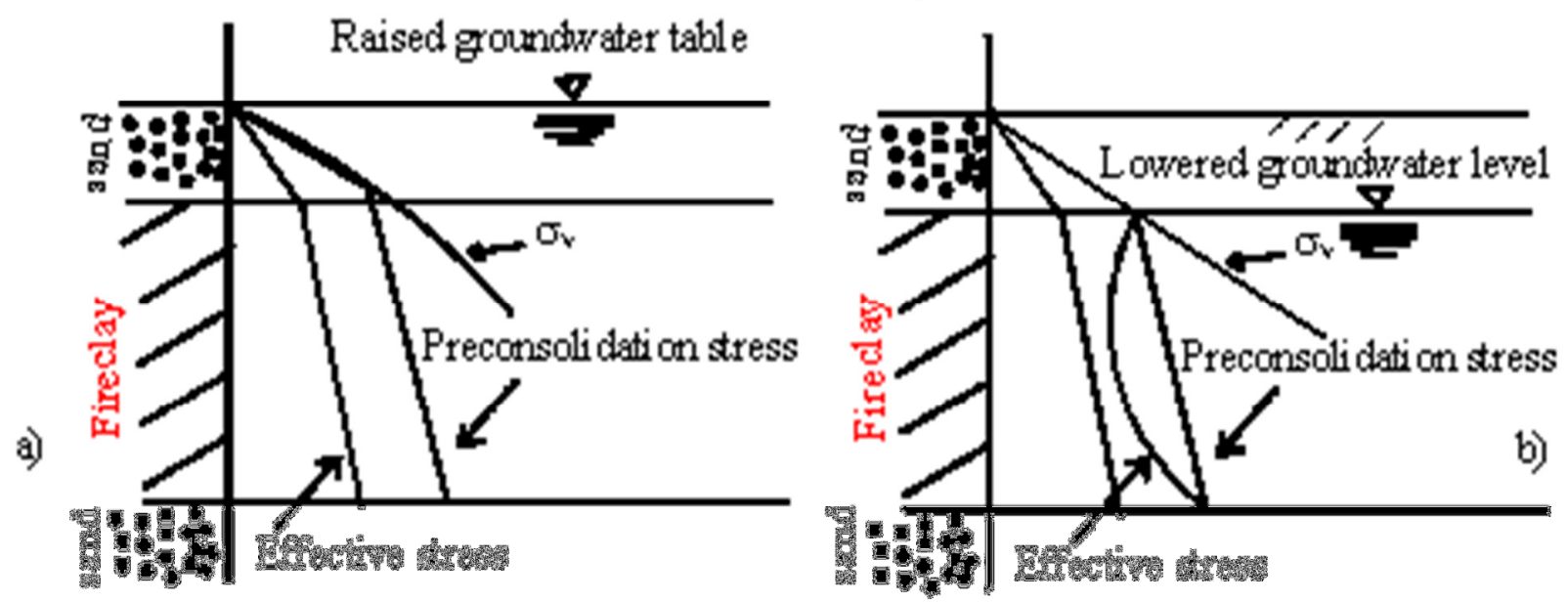

Figure 9: Potential of groundwater level in effecting overconsolidation in the source materials of the wastes [11]

\section{CONCLUSIONS AND RECOMMENDATIONS}

Test results show that the colliery wastes are well graded, low to medium plasticity materials composed mostly of gravel, sand, silt and clay sizes, but with gapgrading about the medium to fine sand fractions for the tailing. The tailing has a particle size gradation shape typical of laterite soils from road sections showing corrugation. The tailing compacts to a higher dry density $\left(1.57 \mathrm{Mg} / \mathrm{m}^{3}\right)$ than the minestone $(1.45$ $\left.\mathrm{Mg} / \mathrm{m}^{3}\right)$. The $\mathrm{pH}$ and sulphate contents of $2: 1$ aqueous extract indicate that normal Portland cement concrete is safe from sulphate attack if placed wholly above the ground water. In fluctuating ground qarter condition sulphate resisting concrete should be used. Under shear stress the mine stone behaved as a purely granular material while the tailing exhibited a cohesive granular behaviour, having both cohesion and internal angle of friction. The low compression index and low coefficient of volume compressibility of the compacted wastes indicate highly incompressible materials.

Laboratory test results largely indicate that the mine stone and the tailing are suitable materials for subgrade, filling and embankment and earth dam construction. Based on the minus No 200 sieve content, the LL and the PI, the mine stone rates suitable as pavement base course material. However, there is the need for caution in the use of laboratory test results to access the suitability of the wastes for engineering works. Mine stones are characteristically susceptible to disintegration during transportation, handling, weathering and compaction, with consequent changes in their physical and mechanical properties. Also in-service weathering and leaching of soluble products leave a more porous product with time. Where fresh mine wastes are used, sulphuric acid generation is likely due to oxidation of the iron sulphide minerals in the wastes. There is then potential for ground water contamination and sulphate attack on concrete in and in contact with the wastes. Even though colliery wastes may meet requirements for a construction, the aforementioned alterations and processes may adversely affect the durability of the product with time. Therefore, reliance on the wastes meeting requirements for a job should be taken with caution. In contrast to this, some problem laterite soils which would have been rejected on the bases of their plasticity characteristics are known to have performed satisfactory as sub base under pavements [8]. This is attributed to their ability to self-stabilise.

\section{REFERENCES}

[1] Kinuthia, J. M. and Gailius, A. "Waste-treated waste: Stabilization of colliery waste from South Wales [UK] using wastepaper sludge ash [WSA]". World of Coal Ash Symp. , April 11-15, Lexington, Kentucky. 2005. 526 pp1-15.

[2] Sherwood, P. "Alternative materials in road construction". Thomas Telford, London.2001.

[3] Sensogut, C. and Ozdeniz, A. H. "Bricks manufactured from colliery wastes: A case study". Int. J. of Mining, Reclamation and Environment. Vol. 20.Issue 4. 2006. pp267-271.

[4] Aggregate Advisory Service (UK)]."The use of coal mining wastes as aggregate." Digest No 066. http:/www.planning.dot.gov.uk/aas/index.htm Accessed on February 3, 2015.

[5] Sagnotti, L. "Iron sulphides". National Institution of Geophysics and Volcanology, Roma, Italy.sagnotti@ingv.it Assessed on July 4, 2014. 
[6] BS 1377. "Methods of tests for classifying soils and obtaining their physical properties". British Standards Institution (BSI), London. 1990.

[7] ASTM D 3080-03. "Test method for direct shear strength test of soils under consolidated drained conditions". ASTM, Philadelphia, PA. 2004.

[8] Gidigasu, M. D. "Laterite soil engineering". Elsevier, Amsterdam, 1976.

[9] Day, R. W. "Foundation engineering handbook". McGraw Hill, New York. 2010.

[10] Tomlinson, M. J."Foundation design and construction". Longman Group, UK. 1993

[11] Chen, W. F. and Liew, J. Y. R. "Civil engineering handbook". CRC Press, Boca Raton. 2003.

[12] Triplett, T. L. and Dreschar, A. 1988. "Analysis of pillar punching into soft claystone in the Southern Illinois". 29th US Symp. on Rock Mech. Minneapolis, MW. June 13-15.1988. pp. 8-17.

[13] Cherry, B. and Petley, D. 2011. "Remembering Aberfan after 45 years ago". Int. Landslide Centre and Inst. of Hazards, Risk and Resilience, Durham University. 2011. pp19-23.

[14] Help Asia News. it "Taoshi disaster in China on December 9, 2008". Accessed on July 17, 2014.

[15] Sutton, B. H. C. "Problem solving in soil mechanics". Longman, London. 1993.

[16] Kogbe, C. A. “Geology of Nigeria”. Rockview, Jos, Nigeria.1989.
[17] Foster, M. H. "The Cretaceous Thermal Maximum and Ocean Anoxic Event 2 in the tropics". Amer. Geophysics Union Falls Meeting . 2006. pp13-20.

[18] Muller, R. D. "Long-term sea level fluctuations driven by ocean basin dynamics". Science. 07, 2008. pp106-112.

[19] Scafetta, N. "Empirical evidence for a celestial origin of the climate oscillations and its implications". J. Atmospheric and Solar-Terrestrial Physics. 73, 2010. pp951-970.

[20] Skarzynska, K. M. "Reuse of coal mining wastes in civil engineering: Properties of minestone". Waste Management, Vol. 15. Issue 1. 1985. pp34-42.

[21] Bell, F. G., Entwisle, D. G. and Cumshaw, M. G. "A geotechnical survey of some BCM mudstone, with particular emphasis on durability". Eng. Geology. $46,1997.115-125$.

[22] United States Agency for International Development (USAID)."Laterites, lateritic soils and other problem soils of Africa". Report AID/C 50 - 2164.1971. 290 pp. 588

[23] Winter, M. G. and Henderson, C. "Recycled aggregates in Scotland". Scottish Executive Central Res. Unit, Edinburgh.2001 . pp1-37.

[24] Grauhalgh, S. A. "Elastic properties of coal measures rocks from South Wales". Australia. J. of Explore. Geophysics. Vol. 17 (2), 1986.pp157-163. 